\title{
Fraudulent Methods Causing False Negatives In Urine Drug Testing
}

\author{
Soycan Mizrak* \\ Clinical Biochemistry Laboratory, Usak Training and Research Hospital, Turkey \\ *Corresponding author: Soycan Mizrak, Clinical Biochemistry Laboratory, Usak Training and Research Hospital, Turkey
}

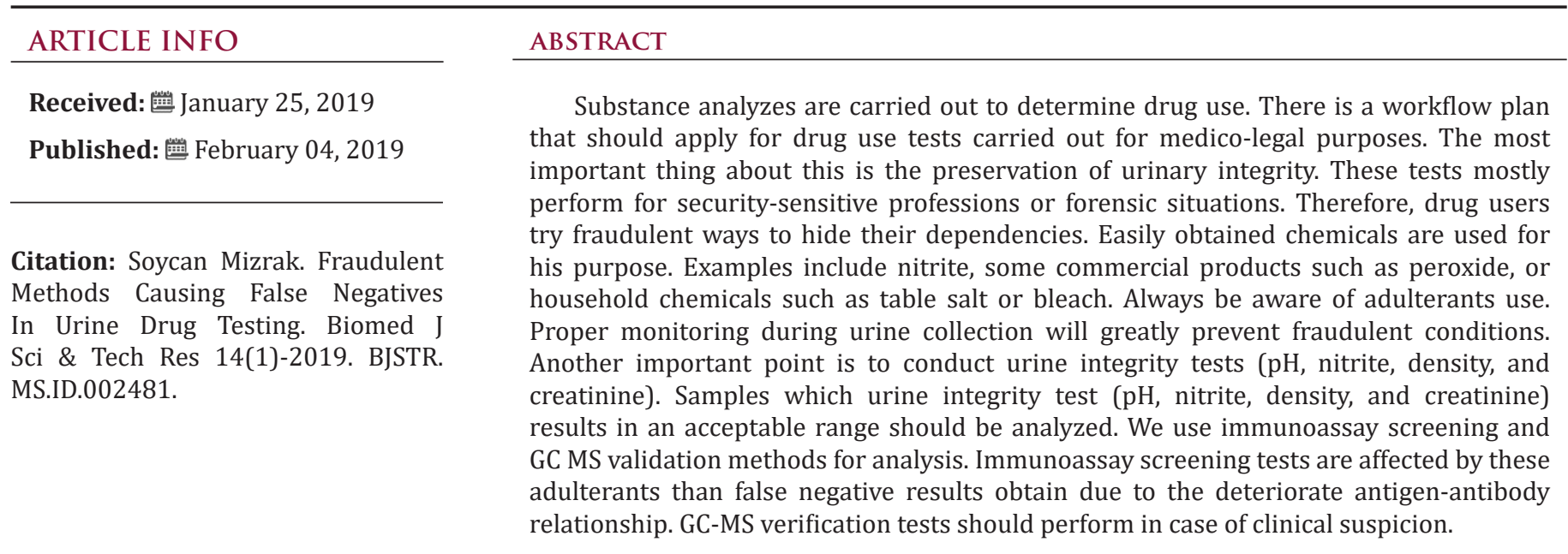

\section{Mini Review}

\section{Fraudulent Methods Causing False Negatives in Urine Drug Testing}

The urine drug test has a significant role in monitoring the use of legal and illicit substance [1]. Drug testing programs implement for all security-sensitive professions such as military forces, transport industry, the mining industry. Additionally, health care (facilitate treatment of clinical intoxication and rehabilitation programs), detect doping in sports, legal and criminal situations such as postaccident testing, rehabilitation testing of ex-convicts, are common areas for drug testing [2]. Drug testing screening programs are increasing day by day. Urine, blood, hair, saliva, sweat and nail samples are using for substance abuse screening tests. Depending on the method of measuring drug levels, screening tests have different specificity, sensitivity, and accuracy of each sample. The most frequently preferred sample for substance abuse screening test is urine because of its easy collection. Furthermore, urine has longer detection times and higher drug concentrations than blood [3]. At the stage of giving the urine sample can be easily cheated. Illegal drug users try to hide their substance use with adulterants (in vivo or in vitro). In vivo adulteration involves the dilution of urine with water or taking a diüretic substance for increasing the metabolism.

In vitro adulteration is the act of adding foreign chemicals (such as vinegar, table salt, hypochlorite bleach, laundry detergent) to urine samples. Therefore, in order to prevent false negative results, the urine validity tests are used [4]. Studies have been carried out for many years to prevent false negative results by detecting adulteration action to the urine. For this purpose, urine specimen intake and admission procedures were developed. Surveillance of urine collection is the most important step. If we make this step meaningfully, we prevent urinary substitution and in vitro adulteration. The other steps of urine integrity tests are temperature, specific gravity, $\mathrm{pH}$, nitrite and creatinine. measurements. Urinary sequencing DNA is the highest accuracy method of urine validation tests [5]. The cross-reaction of a urine adulterant with immunoassay tests include forming insoluble drug analyte-adulterant complexes. In this paper, I describe the oxidizing and non-oxidizing chemical adulterants which cross-react with the immunoassay method. 


\section{Oxidizing Chemicals}

Nitrit: Nitrite in urine is caused by nitrate reducing pathogens in urinary tract infections. However, the commercial products KLEAR and Whizzies can purchase from markets and they contain potassium nitrite $\left(\mathrm{KNO}_{2}\right)$ and sodium nitrite $\left(\mathrm{NaNO}_{2}\right)$, respectively [6].The advantage of nitrite adulterantis that it is easy to use and does not cause any changes in urine appearance. Nitrite analysis can be performed semiquantitatively by urine test strips or quantitatively by automated colorimetric methods. According to the increasing level of nitrite in urine when kept in room temperature for 6 or 8 days, it can be differentiated from the externally added commercial nitrite [7]. Nitrite ion can cause inconsistent results especially for cannabis testing, between the immunoassay screening and gas chromatographic-mass spectrometric (GC-MS) confirmation in urine. False negative immunoassay and GC-MS results obtain due to acidic $\mathrm{pH}$ and urine waiting time (more than four hours). However, in the alkaline pH urine, the immunoassay results were not significantly altered, while GC-MS results were affected. For this reason, we can alkalize urine to prevent false negative results in the immunoassay screening tests [7].

Peroxides: Peroxide-containing urine adulterants are highly effective for masking the presence of cocaine and opiates on screening and confirmatory assays. If we add four or five drops peroxide in urine, a dark brown color is performed due to the reduction of heptavalent chromium by hydrogen peroxide. Stealth is a combination of peroxide and peroxidase. The extent of successful concealment of opiates was inversely related to opiate concentration $[8,9]$.

Pyridinium Chlorochromate (PCC): PCC was found to effectively produce false negative results for cocaine and amfetamine in Both Screening and Confirmatory Assays. PCC is commercially sold as Urine Luck, Klear II. The interference mechanism appears not to be a chemical change in the target drug but a decrease in standard pH levels of samples adulterated with PCC [9].

Gluteraldehyde: It was one of the earliest commercially adulterants, has sold as Clean X or Urine aid. These products cause interferences in immunoassay methods by decreasing absorbance rates, especially in cannabis tests. Additionally, glutaraldehyde didn't affect GC-MS results [10].

\section{Non-oxidizing Adulterants}

Table salt: Drug binding by changing protein structures [11]. Therefore, table salt affects the immunassay results and its high doses produce false negative results. Studies have shown that sodium chloride increases urine density, which is one of the urine validation tests [12].

Detergant/Soap: These cleaning products are including surfactants and alkaline builders. Soap affects the drug binding on immunassays by changing the $\mathrm{pH}$ of the urine sample. Soaps and detergents cause false negative results for amphetamine, barbiturate, cannabis and cocaine [12].

Sodium Hydroxide: Drano drain cleaner is solid sodium hydroxide and it is consisting in variations of sodium hydroxide (lye), sodium hypochlorate (bleach), sodium nitrate, sodium chloride (salt) and aluminum. Sodium hydroxide is a caustic strong base. It causes change to alkaline $\mathrm{pH}$ in urine samples, then it effects the drug binding and solubility and produces false negative urine results [13].

Vinegar: Vinegar is a hydrous solution of acetic acid and called ethanoic acid or methane carboxylic acid. It decreases the urine $\mathrm{pH}$ levels, then effects the drug binding on immunassay methods. Drug addicts use vinegard as a drug detox product. Vinegar distrupts the antigen-antibody association and effects especially amphetamine and cannabis results [11]. It was suggested that GC-MS confirmation test results aren't effected by non-oxidizing adulterans. Adding sodium hydrosulfide or sulfamic acid to the GC-MS method can help remove excess oxidizing additive and may prevent further oxidation of unchanged opium analytes in the sample, thus the accuracy of GC-MS results is less affected by oxidizing adulterans [13].

\section{Conclusion}

To prevent false negative results, it is important to apply the appropriate urine collection procedure. Not to forget the importance of surveillance while obtaining the sample because it is hard to detect the adulterants in analytical and post-analytical phase. Specimen integrity tests reduce false negative results. Also, in case of clinical suspicion, a validation test should be performed with the GC-MS method.

\section{References}

1. Fu S, Luong S, Pham A, Charlton N, Kuzhiumparambil U, et al. (2016) Bioanalysis of urine samples after manipulation by oxidizing chemicals: technical considerations Bioanalysis 2014 6(11):1543-1561.

2. Santoro P, Nardis I, Fronterre P, Felli M, Martello S, et al. (2012) snapshot of workplace drug testing in Italy. Drug Test Anal 4(2): 66-70.

3. Karen E, Kelly C, Julie C (2008) Urine Drug Screening: Practical Guide for Clinicians. Mayo Clinic Proceedings 83(1): 66-76.

4. Jaffee W, Trucco E, Levy S, Weiss R (2007) Is this urine really negative? A systematic review of tampering methods in urine drug screening and testing. J Subst Abuse Treat 33(1): 33-42.

5. Fu S (2014) Adulterants in Urine Drug Testing. Adv Clin Chem 76: 123163.

6. EISohly M, Feng S, Kopycki W, Murphy T, Jones A, et al. (1997) A procedure to overcome interferences caused by the adulterant "Klear" in the GC-MS analysis of 11-nor-A THC-9-COOH. J Anal Toxicol 21(3): 240-242.

7. Tsai J, ElSohly M, Tsai S, Murphy T, Twarowska B, et al. (2000) Investigation of Adulteration on the Immunoasay and GC-MS Analysis of Cannabinoids in Urine Specimens. J Anal Toxicol 24(8): 708-714.

8. Wong R (2002) The effect of adulterants on urine screen for drugs of abuse: detection by an on-site dipstick device. Am Clin Lab 21(1): 37-39.

9. Wu A, Bristol B, Sexton K, Cassella G, Holtman V, etal. (1999) Adulteration of urine by "Urine Luck". Clin Chem 45(7): 1051-1057. 
10. Goldberger B, Caplan Y (1994) Effect of glutaraldehyde (UrinAid) on detection of abused drugs in urine by immunoassay. Clin Chem 40(8): $1605-1606$

11. Mikkelsen S, Ash K (1988) Adulterants causing false negatives in illicit drug testing. Clin Chem 34(11): 2333-2336.

ISSN: 2574-1241

DOI: 10.26717.BJSTR.2019.14.002481

Soycan Mizrak. Biomed J Sci \& Tech Res

\section{(c) (i) This work is licensed under Creative}

Submission Link: https://biomedres.us/submit-manuscript.php
12. Schwarzhoff R, Cody J (1993) The effects of adulterating agents on FPIA analysis of urine for drugs of abuse. J Anal Toxicol 17(1): 14-7.

13. Wu A (2003) Urine adulteration and substitution prior to drugs of abuse testing. J Clin Ligand Assay 26(1): 11-18.

$\begin{array}{ll}\text { BIOMEDICAL } & \text { Assets of Publishing with us } \\ \text { RESEARCHES } & \text { - Global archiving of articles } \\ & \text { - Immediate, unrestricted online access } \\ & \text { - Rigorous Peer Review Process } \\ \end{array}$

